\title{
A Meta-Analysis: The Effects of Child Sexual Abuse Towards Children
}

\author{
Nurul Farhana Binti Zainudin ${ }^{1} \&$ Zakiah Binti Mohamad Ashari $^{1}$ \\ ${ }^{1}$ Faculty of Education, Universiti Teknologi Malaysia, Johor, Malaysia \\ Correspondence: Nurul Farhana Binti Zainudin, Faculty of Science Social and Humanities, Universiti Teknologi \\ Malaysia, Johor, Malaysia. Tel: 60-196-881-381. E-mail: nfarhana265@ graduate.utm.my
}

Received: August 1, 2018

doi:10.5539/ass.v14n11p69
Accepted: September 1, 2018

Online Published: October 22, 2018

URL: https://doi.org/10.5539/ass.v14n11p69

\begin{abstract}
Recently, cases of sexual abuse against children became a phenomena and it is a traumatic events that give a deep impact towards the victim. Therefore, the purpose of this study was to conduct a meta- analysis on a published researched about effects of child sexual abuse towards children. There were 20 journal articles collected from Science Direct, SpringerLink, Willey Online Library and Web of Science databases with the keywords 'child sexual abused' 'behavior', 'emotional', 'social' and 'academic' being used. The year of papers selected were from 2010 until 2017. The researcher differentiated and analyzed the effect of child sexual abuse toward four themes: internalizing and externalizing behavior, emotional regulation, suicidal behavior and academic achievement and performance. The findings from this study shown that child with previous experiences as victims in child abuse display internalizing and externalizing behavior and poor on academic achievement and performance. The findings also shown that the sexually abused children especially girls has low emotional regulation and the victims also had suicidal ideation and suicidal attempt. The implication from this study was to provide the insight for future researchers on the effects of child sexual abuse in behavior, emotional, social and academic aspects. Since this study only focused on the effect of sexual abuse towards children, it was suggested that for future researches, the effects of sexual abuse towards different range of age such as adult with history of sexual abused should be further investigated and more effects apart from behavioral, emotional, social and academic should be considered.
\end{abstract}

Keywords: child sexual abuse, behaviour, emotional, social, academic

\section{Introduction}

Recently, cases of child sexual abuse became a phenomena and widespread throughout the world with prevalence rates ranging between $8-31 \%$ for females and 3-17\% for males (Barth, Bermetz, Heim, Trelle, \& Tonia, 2013). This is seriously an alarming high prevalence rates. The Federal Child Abuse Prevention and Treatment Act defines child abuse and neglect as "any recent act or caretaker which result in death, serious physical or emotional harm, sexual abuse or exploitation, an act or failure to act which presents an imminent risk of serious harm". Child abuse can be differentiated by three types which were physical abuse, psychological abuse and sexual abuse that will be the focus of this study. Sexual abuse is defined as "the abuse of a child or adolescent who has not achieved sexual maturation by an adult for fulfillment of sexual desires and needs by use of force, threat, deception or other kinds of manipulation" (İșeri, 2008). Therefore, child sexual abuse (CSA) cannot be ignored due to its potential to contribute numerous effects towards the victims whether in male or female.

There were many studies about the effects of child sexual abuse towards the victims with different types of variables such as the study from (Fergusson, McLeod, \& Horwood, 2013) stated that depression, anxiety, low self-esteem, suicide attempts, as well as alcohol and drug dependence is the risk factor of childhood sexual abuse. The children who exposed with sexual abuse are likely to show posttraumatic stress disorder (PTSD) symptoms (Hébert, Langevin, \& Daigneault, 2016). Based on past study, experiencing abuse such as physical, emotion and sexual abuse give a negative impact on the development of emotion regulation (Langevin, Cossette, \& Hébert, 2016; Langevin, Hébert, \& Cossette, 2015). For the meta-analysis or systematic review studies about this effects of child sexual abuse, they were rarely founded. But, there was this one study that doing a research regarding this topic by (Kendall-Tackett, Williams, \& Finkelhor, 1993). In their systematic review, Kendall-Tackett and colleagues examined 45 studies and calculated that $64-79 \%$ of children who disclosed with sexual abuse display psychological symptom such as low self-esteem, anxiety, fear, suicidal ideation and attempts, somatic complaints, 
aggressive behavior, running away from home, and substance abuse. The child sexual abuse also gives an impact towards children academic achievement and academic performance (Boden et al., 2007).

Although there were many studies about the effects of child sexual abuse, not many researcher done the meta-analysis studies and even it was exists the studies were far from recent years. Therefore, the author decided to study the effects on child sexual abuse towards children and came out with a table of meta-analysis at the end of this study. In addition, the author also aim to update the literature regarding this topic.

\section{Method}

There were three stages of methodology in this study which were literature search, selection process and lastly was data selection. All of this process will be explained more below.

\subsection{Literature Search}

The search strategy for this study were selection of publication from several databases using computer. The articles journal about the effects of child sexual abuse towards children were acquired through searching from Web of Science, Wiley Online Library, Science Direct, SpringerLink and Taylor and Francis Online. The articles published date from year 2010 until 2017 and only limited to English language will be selected. All publications were searched using the keywords "child sexual abuse", "behavior", "social", "emotion" and "academic". The screening process examined titles, abstracts, and full-text of potential articles and was conducted by the author to ensure all eligible articles were included. There were about 150 articles were screened during the search in the databases.

\subsection{Selection Process}

For the selection process, the articles were included if they met the eligibility criteria: 1) The sample of the study is the children aged from 4 to 18 years old; 2) The year of publications were 2010 onwards; 3) The articles have these variables which are child sexual abuse, behavior, emotion, social and academic achievement; 4) The articles were in English language only. The author investigated publications independently and any discrepancies the authors will discuss with co-author and solved it together. The author also categorized all the publication and organized them into different folders for each variables to avoid confusion. In the end of selection process, total of 20 articles were selected.

\subsection{Data Extraction}

For data extraction, relevant information from the included studies was independently extracted. When there was a disagreement regarding whether a study should be included for analysis, the primary author made the final decision. The following information was extracted from each eligible study: author's name, year of publication and the findings of each study. The authors read thoroughly the full text articles to identify the findings for each publications. In the end of the process, the author came out with the table of meta-analysis regarding the issues to be discussed.

\section{Result}

Below is the table of meta-analysis for effects of child sexual abuse towards the children. Next, the process of literature search, selection process and data extraction, the author came out with this table which were divided according to the four themes which were social, behavior, emotion and academic. There were total of 20 publications selected by the author. There were specification founded for each theme which were social are suicide attempt and suicide ideation, emotion is emotional regulation, behavior are internalizing and externalizing behavior and academic is academic achievement and performance. The overall results will be discussed on discussion section.

Table 1. Table of Meta-Analysis: The Effects of Child Sexual Abuse towards Children

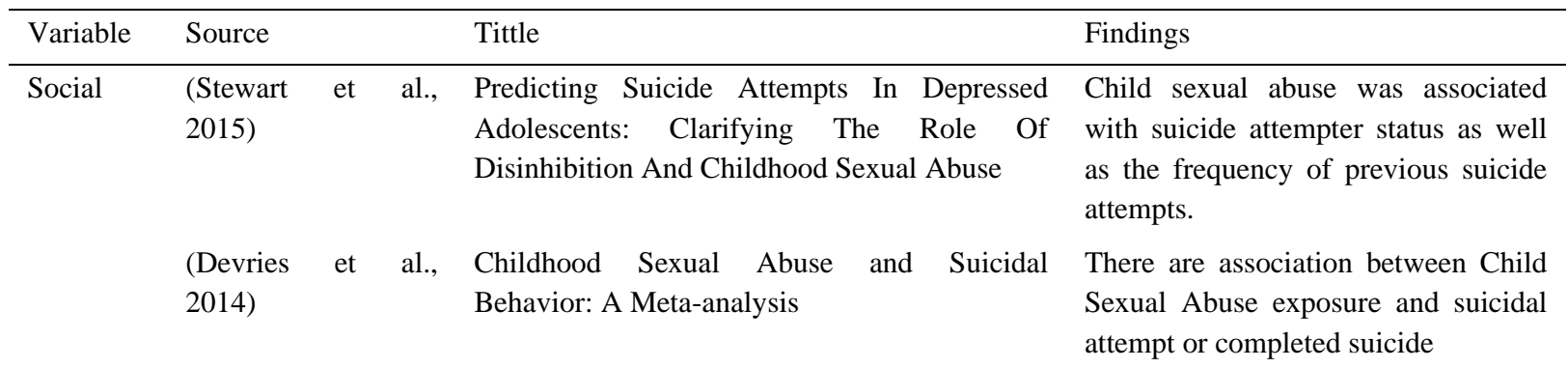


(Soylu \& Alpaslan, Suicidal Behaviour And Associated Factors In 2013) Sexually Abused Adolescents

(Sigfusdottir, Asgeirsdottir, Gudjonsson, Sigurdsson, 2013)

Suicidal ideations and attempts among adolescents subjected to childhood sexual \& abuse and family conflict/violence: The mediating role of anger and depressed mood

(Lin, Li, Fan, \& Child Sexual Abuse And Its Relationship With Fang, 2011) Health Risk Behaviors Among Rural Children And Adolescents In Hunan, China

(Maikovich-Fong \& Sex Differences in Childhood Sexual Abuse Jaffee, 2010) and

Suicide-Related Behaviors

Emotion

(Séguin-Lemire, Hébert, Cossette, \& Langevin, 2017)

(Langevin, Cossette, Emotional Regulation In Sexually Abused \& Herbert, 2016) Preschooler

(Langevin et al, Emotion Regulation In Sexually Abused 2016)

(Choi \& Oh, 2014) Factor

Cumulative Childhood Trauma And Psychological Maladjustment Of Sexually Abused Children In Korea: Mediating Effects Of Emotion regulation

Behavior (Gauthier-Duchesne, Gender As A Predictor Of Posttraumatic Stress Hébert, \& Daspe, Symptoms And Externalizing Behaviour 2017)

Problems In Sexually Abused Children

(Lewis, McElroy, Does The Impact Of Child Sexual Abused Harlaar, \& Runyan, Children? A Prospective Examination Of The 2016)

(Katz \& Barnetz, The Behavior Patterns Of Abused Children As 2014)

(Jones et al., 2013)
Described In Their Testimonies Impact Of Child Sexual Abuse On Internalizing And Externalizing Behaviour Problems

Linking Childhood Sexual Abuse And Early Adolescent Risk Behavior: The Intervening Role Of Internalizing And Externalizing Problems
Suicidal behaviour was more frequently in victims exposed to abuse involving contact and penetration and also experienced Sexual Abuse more than one.

The exposures to family conflict/violence and sexual abuse lead to depressed mood and anger as well as suicidal ideations and suicide attempts.

The CSA associated with smoking, binge eating, suicidal ideation and suicidal attempts.

The boys students sexually abused showed stronger association in suicide attempts compare to girls students who have been sexually abused

Sexually abused children had lower emotion regulation competencies compare to non-abused children.

Both parents and educators reported lower emotion regulation competencies in sexually abused preschoolers, especially boys, than in non-abused children

Boys have lower emotional regulation than girls.

The sexually abused children with more serious and long duration of trauma were found to have more serious impact to their emotional regulation ability.

The sexually abused boys were more likely to display externalizing behaviour problems

Those with a history of sexual abuse had significantly greater externalizing and internalizing problems over time compared those without sexual abuse histories.

The sexual abused child group reporting more fight and flight behaviour while children in the physical abuse group reporting more self-change behaviour.

The results for externalizing behaviour in terms of sexual intercourse, both gender boys and girls shown indirect effect from CSA to sexual intercourse. 
(Maikovich-Fong \& Sex Differences In Childhood Sexual Abuse Jaffee, 2010) Characteristics And Victims' Emotional And Behavioural Problems: Findings From A National Sample Of Youth

Academic (Mugabe, 2016)

(Azi \& Saluhu, 2016)

Psychosocial Effects Of Child Sexual Abuse On The Academic Performance Of Grade Seven Learners In Gweru Urban, Zimbabwe

(Adigeb \& Mbua, 2015)

(McLean, Rosenbach, Capaldi, \& Foa, 2013)

The effect of Child Abuse on the Academic Performance of School Children: Implication on the Nigerian Economy

Child Abuse And Students Academic Performance In Boki Local Government Area Of Cross River State

Social and Academic Functioning in Adolescents with Child Sexual Abuse-Related PTSD

(Huang \& Mossige, 2012)
Academic achievement in Norwegian secondary schools: the impact of violence during childhood
There were not any sex differences in the severity of internalizing, externalizing and trauma symptoms.

There are impact of child sexually abused affect the academic performance.

The findings revealed that children who have been abused less performed academically than non-abused.

The sexual abuse of children has a significant relationship with students' academic performance.

The findings showed that greater PTSD symptom severity due to CSA does not related with the poorer academic functioning.

The young victims expose to violence and sexual abuse have negative effect on academic achievement.

\section{Discussion}

Child sexual abuse is a traumatic phenomenon that have been a widespread in the world. These events have highly adverse impact towards everyone especially the victims. The results from the meta-analysis have shown that the researcher has come out with four themes which are social, emotion, behavior and academic achievement. There are total of six studies for social, four studies for emotion and five studies for both behavior and academic achievement. For each theme, the author found the similarities and differences for each study that will be discussed later. In this section also, the author will discussed the limitation and the strength of this study.

The first theme was social and the author found that every studies selected were related with suicide. Based on the analysis, it was discovered that social effects of child sexual abuse towards children was suicide which were consists of suicide ideation and suicide attempt. It can be justified based on this study from (Sigfusdottir et al., 2013) stated that the exposures to family conflict/violence and sexual abuse lead to depressed mood and anger as well as suicidal ideations and suicide attempts. Suicidal behaviour was more frequently in victims exposed to abuse involving contact and penetration and also experienced sexual abuse more than one (Soylu \& Alpaslan, 2013). Based on the author perspectives, the victims or children who have been sexually abused are tend to attempt suicide or have suicide ideation because they feel they have lost everything in their life. Moreover, on such a young age, this event could give a very huge damage and impact to their well-being.

The second theme is emotion and the studies selected were specifically focused on emotion regulation. Emotion regulation has been defined as "the extrinsic and intrinsic processes responsible for monitoring, evaluating, and modifying emotional re- actions, especially their intensive and temporal features, to accomplish one's goals."(pp. 27-28). The study founded that sexually abused children had lower emotion regulation competencies compare to non-abused children (Séguin-Lemire et al., 2017). The sexually abused children with more serious and long duration of trauma were found to have more serious impact to their emotional regulation ability (Choi \& Oh, 2014). The author realized that emotion regulation is very important to every human being. The sexually abused children have impact on their emotion regulation due to trauma of the sexual abuse event. So that, it makes their emotion cannot differentiate and react according to the certain situation.

The third theme is behaviour and the studies selected were focusing on internalizing and externalizing behaviour which was known as psychiatric symptoms. Based on the theoretical framework of Developmental of Psychopathology, the externalizing and internalizing behaviour can be defined as undercontrolled and overcontrolled, of behaviour, emotion and thoughts respectively (Achenbach \& Edelbrock, 1978; Achenbach, Howell, Quay, \& Conners, 1991). Based on analysis, those with a history of sexual abuse had significantly greater externalizing and internalizing problems over time compared those without sexual abuse histories (Lewis 
et al., 2016). The study also revealed that there were not any sex differences in the severity of internalizing, externalizing and trauma symptoms (Maikovich-Fong \& Jaffee, 2010). The example of externalizing behaviour are delinquency and bullying while internalizing is isolation from others. The victims showed these behaviour because of sense of guilt and feel ashamed with others such as peers. The traumatic event happen to the victims caused them to express their feelings by doing such behaviors.

The forth theme is academic which can be differentiated by academic achievement and academic performance. Academic achievement is the accomplishment at the end of the course while academic performance is the observed behaviour in achieving specific task (Yusuf, 2002). Based on the study selected, there are impact of child sexually abused on the academic performance (Mugabe, 2016). The young victims expose to violence and sexual abuse have negative effect on academic achievement (Huang \& Mossige, 2012). The students also the victims has poor academic achievement and academic performance due to after effects of sexual abuse towards them. Every students need a healthy mental and physical for focusing in their studying but if that particular students is one of the sexual abused victims, their emotion and cognitive are surely disturbed and as a result affect their academic achievement as well as performance.

There were several limitations by conducting this study. First was the number of publications is small which was only 20 publications. It was not strong enough to summarize and represent these four themes which were emotion, social, behaviour and academic. Second, the publication only focusing on children and adolescent so that, it cannot be generalized to other range of age. Third, this study only focusing on themes and not measured the effects size which can be more detailed and complete for this study. Despite that, there was one strength of this study which was this study successfully come out with a complete table of meta-analysis regarding the effects of child sexual abuse towards children. It gives a huge contribution to the literature about this topic.

\section{Conclusion}

Based on this study, the author successfully came out with a table of meta-analysis regarding the effects of child sexual abuse towards children. There were total of 20 publications selected from various databases. At the end of this studies, there were four outcomes or themes which were social (suicide attempt and suicide ideation), emotion (emotional regulation), behavior (internalizing and externalizing behavior) and academic (academic achievement and performance). These four themes were discovered after thoroughly analysis and summarization from the author after several period of time for completion this study.

There were several implication that can be taken from this study and first, this study will give insight for future research in conducting their studies regarding this topic by referring this study. This study also gave implication to the researcher who was interested to study about the prevention of child sexual abuse because before the prevention they should aware the effects of the child sexual abuse. Lastly, in education setting this study will give insight to the educator about the child sexual abuse and its relation with academic achievement and academic performance.

For future research, the author suggesting to make another meta-analysis but focusing different range of age such as adult who have been experiencing child sexual abuse. In addition, the author also suggest for further research of different effects of child sexual abuse such as PTSD, self-esteem and internet addiction.

\section{References}

Achenbach, T. M., \& Edelhrock, C. (1978). The classification of child psychopathology: A review and analysis of empirical efforts. Psychological Bulletin, 85, 1275-1301.

Achenbach, T. M., Howell, C. T., Quay, H. C., \& Conners, C. K. (1991). National survey of problems and competencies among four- to sixteen-year-olds: Parents' reports for normative and clinical samples. Monographs of the Society for Research in Child Development, 56, 1-131.

Adigeb, A. P., \& Mbua, A. P. (2015). Child Abuse and Students Academic Performance in Boki Local Government Area of Cross River State. British Journal of Education, 3(3), 34-42.

Azi, A. S., \& Saluhu, A. I. (2016). The Effect of Child Abuse on the Academic Performance of School Children : Implication on the Nigerian Economy. Asia Pacific Journal of Education, Arts and Sciences, 3(3), 23-27.

Barth, J., Bermetz, L., Heim, E., Trelle, S., \& Tonia, T. (2013). The current prevalence of child sexual abuse worldwide: A systematic review and meta-analysis. International Journal of Public Health, 58(3), 469-483. https://doi.org/10.1007/s00038-012-0426-1Bergen

Boden, J. M., Horwood, L. J., \& Fergusson, D. M. (2007). Exposure to childhood sexual and physical abuse and subsequent educational achievement outcomes. Child Abuse \& Neglect, 31, 1101-1114. 
Child Welfare Information Gateway. (2013). What is child abuse and neglect? Recognizing the signs and symptoms. Washington, DC: U.S. Department of Health and Human Services, Children's Bureau.

Choi, J. Y., \& Oh, K. J. (2014). Cumulative childhood trauma and psychological maladjustment of sexually abused children in Korea: Mediating effects of emotion regulation. Child Abuse and Neglect, 38(2), 296-303. https://doi.org/10.1016/j.chiabu.2013.09.009

Devries, K. M., Mak, J. Y. T., Child, J. C., Falder, G., Bacchus, L. J., Astbury, J., \& Watts, C. H. (2014). Childhood Sexual Abuse and Suicidal Behavior: A Meta-analysis. Pediatrics, 133(5), e1331-e1344. https://doi.org/10.1542/peds.2013-2166

Fergusson, D. M., McLeod, G. F., \& Horwood, L. J. (2013). Childhood sexual abuse and adult developmental outcomes: Findings from a 30-year longitudinal study in New Zealand. Child Abuse \& Neglect, 37(9), 664-674. https://doi.org/10.1016/j.chiabu.2013.03.013

Gauthier-Duchesne, A., Hébert, M., \& Daspe, M.-È. (2017). Gender as a predictor of posttraumatic stress symptoms and externalizing behavior problems in sexually abused children. Child Abuse \& Neglect, 64, 79-88. https://doi.org/10.1016/j.chiabu.2016.12.008

Hébert, M., Langevin, R., \& Daigneault, I. (2016). The association between peer victimization, PTSD, and dissociation in child victims of sexual abuse. Journal of Affective Disorders, 193, 227-232. https://doi.org/10.1016/j.jad.2015.12.080

Huang, L., \& Mossige, S. (2012). Academic achievement in Norwegian secondary schools: The impact of violence during childhood. Social Psychology of Education, 15(2), 147-164. https://doi.org/10.1007/s11218-011-9174-y

İşeri, E. (2008). Sexual abuse. In F. Ç. Çetin, B. Pehlivantürk, F. Ünal, R. Uslu, E. İşeri, \& T. Türkbay (Eds.), The handbook on child and adolescent psychiatry (pp. 470-477). Ankara: Hekimler Yayın Birliği Press.

Jones, D. J., Lewis, T., Litrownik, A., Thompson, R., Proctor, L. J., Isbell, P., ... Runyan, D. (2013). Linking childhood sexual abuse and early adolescent risk behavior: The intervening role of internalizing and externalizing problems. Journal of Abnormal Child Psychology, 41(1), 139-150. https://doi.org/10.1007/s10802-012-9656-1

Katz, C., \& Barnetz, Z. (2014). The behavior patterns of abused children as described in their testimonies. Child Abuse and Neglect, 38(6), 1033-1040. https://doi.org/10.1016/j.chiabu.2013.08.006

Kendall-Tackett, K. A., Williams, L. M., \& Finkelhor, D. (1993). Impact of sexual abuse on children: A review and synthesis of recent empirical studies. Psychological Bulletin, 113, 164-180.

Langevin, R., Cossette, L., \& Hébert, M. (2016). Emotion regulation in sexually abusedpreschoolers. Child Psychiatry \& Human Development, 47(1), 1-12. https://doi.org/10.1007/s10578-015-0538-y

Langevin, R., Hébert, M., \& Cossette, L. (2015). Emotion regulation as a mediator of the relation between sexual abuse and behavior problems in preschoolers. Child Abuse \& Neglect, 46, 16-26, https://doi.org/10.1016/j.chiabu.2015.02.001.

Lewis, T., McElroy, E., Harlaar, N., \& Runyan, D. (2016). Does the impact of child sexual abuse differ from maltreated but non-sexually abused children? A prospective examination of the impact of child sexual abuse on internalizing and externalizing behavior problems. Child Abuse \& Neglect, 51, 31-40. https://doi.org/10.1016/j.chiabu.2015.11.016

Lin, D., Li, X., Fan, X., \& Fang, X. (2011). Child sexual abuse and its relationship with health risk behaviors among rural children and adolescents in Hunan, China. Child Abuse \& Neglect, 35(9), 680-687. https://doi.org/10.1016/j.chiabu.2011.05.006

Maikovich-Fong, A. K., \& Jaffee, S. R. (2010). Sex differences in childhood sexual abuse characteristics and victims' emotional and behavioral problems: Findings from a national sample of youth. Child Abuse and Neglect, 34(6), 429-437. https://doi.org/10.1016/j.chiabu.2009.10.006

McLean, C. P., Rosenbach, S. B., Capaldi, S., \& Foa, E. B. (2013). Social and academic functioning in adolescents with child sexual abuse-related PTSD. Child Abuse and Neglect, 37(9), 675-678. https://doi.org/10.1016/j.chiabu.2013.03.010

Mugabe, M. S. C., \& K. C. (2016). Psychosocial Effects of Child Sexual Abuse on the Academic Performance of Grade Seven Learners in Gweru Urban, Zimbabwe. Journal of Emerging Trends in Educational Research and Policy Studies (JETERAPS), 7(4), 255-263. 
Séguin-Lemire, A., Hébert, M., Cossette, L., \& Langevin, R. (2017). A longitudinal study of emotion regulation among sexually abused preschoolers. Child Abuse \& Neglect, 63, 307-316. https://doi.org/10.1016/j.chiabu.2016.11.027

Sigfusdottir, I. D., Asgeirsdottir, B. B., Gudjonsson, G. H., \& Sigurdsson, J. F. (2013). Suicidal ideations and attempts among adolescents subjected to childhood sexual abuse and family conflict/violence: The mediating role of anger and depressed mood. Journal of Adolescence, 36(6), 1227-1236. https://doi.org/10.1016/j.adolescence.2013.10.001

Soylu, N., \& Alpaslan, A. H. (2013). Suicidal behavior and associated factors in sexually abused adolescents. Children and Youth Services Review, 35(2), 253-257. https://doi.org/10.1016/j.childyouth.2012.11.002

Stewart, J. G., Kim, J. C., Esposito, E. C., Gold, J., Nock, M. K., \& Auerbach, R. P. (2015). Predicting suicide attempts in depressed adolescents: Clarifying the role of disinhibition and childhood sexual abuse. Journal of Affective Disorders, 187, 27-34. https://doi.org/10.1016/j.jad.2015.08.034

Thompson, R. A. (1994). Emotion regulation: a theme in search of definition. Monogr Soc Res Child Dev, 59, 25-52. https://doi.org/10.1111/j. 1540-5834.1994.tb01276.x

Yusuf, A. (2002). Inter-relationship among academic performance, academic achievement and learning outcomes. Journal of Curriculum and Instruction, 1 and 2, 87-96.

\section{Copyrights}

Copyright for this article is retained by the author(s), with first publication rights granted to the journal.

This is an open-access article distributed under the terms and conditions of the Creative Commons Attribution license (http://creativecommons.org/licenses/by/4.0/). 